\title{
A Healthy Planet Supports Healthy People
}

Note: The numbers in brackets \{\} throughout this Technical Summary refer to the sections of the main Global Environment Outlook (GEO-6) report (UNEP 2019a) and its Summary for Policy Makers (SPM) (UNEP 2019b) where more detail on the points made here, including references to the scientific literature, may be found. Further scientific references have been limited to work published in 2018, which had not appeared by the time GEO-6 was finalised, and more recently.

The sixth Global Environment Outlook (GEO-6) assesses the state of the environment, the effectiveness of policy and other responses in addressing environmental challenges, and the possible pathways for achieving various internationally agreed environmental goals. It differs from and complements other global assessments (see Annex 1) in its scope and integrated nature. GEO-6 is more holistic in its analysis, whereas other assessments tend to focus more narrowly on, for example, biodiversity and ecosystem services (the Intergovernmental SciencePolicy Platform on Biodiversity and Ecosystem Services [IPBES]), climate change (the Intergovernmental Panel on Climate Change [IPCC]) or the marine environment (the World Ocean Assessment).

The GEO-6, entitled Healthy Planet, Healthy People (United Nations Environment Programme [UNEP] 2019a) and its Summary for Policymakers (UNEP 2019b), provides evidence-based environmental information to help policymakers and other decision makers to achieve the environmental mandates of the 2030 Agenda for Sustainable Development (Agenda 2030) and its Sustainable Development Goals (SDGs), together with other internationally agreed environmental goals, as well as to implement multilateral, regional and global environmental agreements. The theme Healthy Planet, Healthy People links the environmental dimension of the SDGs to their human and social dimensions. GEO- 6 assesses recent scientific knowledge and data, analyses current and past environmental policies (including their objectives and consequences), and identifies options to achieve sustainable development by 2050. \{Chapter 1; Summary for Policymakers [SPM]\}. This explains why there have been changes in the context, focus and methods of GEO- 6 compared with previous GEOs.

This Technical Summary synthesizes the key evidence and messages of GEO-6. Chapter 1 sets out the context and methodological approach of the GEO-6 assessment. It is followed by chapters that:

* discuss the five drivers affecting the health of the planet: trends in human population, combined with economic development; growth of consumption; rapid urbanization; accelerating technological innovation; and climate change (Chapter 2);

- review the impacts of broad systemic activities (called cross-cutting issues in the GEO-6) and the health, equity and economic dimensions of these impacts (Chapter 3); collectively providing evidence that the planet is becoming increasingly unhealthy;.

- review the literature and undertake case studies on policy implementation to show how policies are struggling to keep up with the rate and scale of planetary degradation (Chapter 4);

* assess the literature to demonstrate that there is a case to be made for transformative change linking the health of the planet to human health (Chapter 5) and

* examine the changing role of knowledge and data for a healthy planet (Chapter 6).

Throughout GEO-6 there is a focus on three key required systemic changes: in the food and energy systems, and in wasteful use of material resources.

Agenda 2030 and its SDGs, adopted in 2015, call for environmental objectives to be better integrated with social and economic objectives. The SDGs follow on from the Millennium Development Goals (MDGs), which between 2000 and 2015 focused global attention on key development objectives. However, the SDGs place 
much more emphasis on the environmental dimension of sustainable development and stress the need for an integrated approach, in all countries, to the social, environmental and economic pillars of sustainable development.

The SDGs emphasize that improving environmental quality globally must be pursued along pathways that ensure that "no one is left behind" - and that activities undertaken to achieve these goals are rooted in human rights and dignity. In order to address the social, environmental and economic dimensions of the SDGs synergistically, they can be grouped according to how they address:

- social objectives or, more broadly, human well-being;

* sustainable consumption and production with respect to resource use and access; and

* protection and management of natural resources and the environment.

To address these goals, options are sought that will yield coherent and integrated progress towards a healthier planet and improved and more equitable human well-being. $\{20.3\}$

\section{Grouping the SDGs and their respective targets according to their area of focus reveals potential synergies, trade-offs and governance linkages between them. It can also demonstrate that the desire for a healthy planet underpins all the SDGs (the environment provides the natural resource base on which human development and well-being are built), and that successful development and improved and more equitable human well-being cannot be sustained if they are obtained at the cost of environmental degradation. Moreover, failure in one direction can compromise progress in another direction. The decrease of the benefits from the environment is already having an adverse impact on people.}

Where people live in poverty and hunger, the limited choices available to them increase pressure on nature and the planet. The linkage between human well-being and its environmental foundation underscores the need for policies that jointly and explicitly focus on sustainable consumption and production, as well as on equitable distribution of access to natural resources and their benefits. Such policies would take advantage of synergies and minimize trade-offs across the SDGs. $\{20.3\}$
The GEO- 6 emphasis on the theme that a healthy planet supports healthy people is in line with the integrated approach of the SDGs. A healthy planet is necessary for human health and well-being - physical, psychological, emotional, social and economic (well established). Plants and animals that live in the physical environment provide us with food, energy and shelter. They clean the air we breathe and the water we drink, among many other essential ecosystem services. The natural environment directly supports the lives and livelihoods of 70 per cent of the proportion of the Earth's population who live in poverty. \{SPM 2.2.2; 6, 6.3.4, 6.6.3; Box: 6.5; Box $13.2\}$ It also provides the basis for the production of the goods and services that underpin the global formal economy, which had a gross world product (GWP) value of US\$ 75 trillion in 2017. Because the biosphere is essential for human survival, there is no meaningful way to assign a monetary value to it. However, the global value of ecosystem services (the benefits provided by nature to human societies and economies) in 2011 has been estimated to be US\$ (2007 dollars) 125 trillion/ year $\{1.3 .1\}$. However, even this estimate does not fully capture, for example, the benefits of a climate suitable for agriculture; the impacts of melting glaciers on the water security of more than a billion people $\{4.2 .2\}$; or the impacts of loss of land and property in coastal megacities as a result of rising sea levels. It is therefore clearly an underestimate. \{Co-Chairs' Message\}

\section{Successive GEO reports and other assessments have shown that there is growing deterioration of the health of the planet, with associated impacts on people (well established). Each GEO report has identified environmental challenges, as well as documented successes and failures in mitigating and preventing health and environmental problems. Many thematic assessments, along with the findings of regional GEOs (UNEP 2016a; UNEP 2016b; UNEP 2016c; UNEP 2016d; UNEP 2016e; UNEP 2016f), were integrated into GEO- 6 . Despite extensive analysis provided by previous assessments - and notwithstanding some policy successes in various areas - GEO-6 demonstrates that major environmental problems persist and, in many cases, are worsening. To find ways to support effective policy choices, including for the public health community, GEO-6 identifies drivers and cross-cutting issues that affect five socio-ecological systems: air, freshwater, land and soil, oceans and coasts, and biodiversity.}

The public health community has long-established ways of reflecting the complex web of relationships between a healthy planet and healthy people (well 
established). GEO-6 treats health in line with the World Health Organization [WHO]'s 1948 definition as "a state of complete physical, mental, and social well-being and not merely the absence of disease or infirmity" (GEO-6 Glossary) and considers wellbeing as having psychological, emotional and social dimensions. GEO-6 also focuses on the determinants of health. It recognizes that human health and wellbeing are mediated by multiple factors in the natural, social and built environments, including our sense of equity and safety, along with equitable access to environmental resources and human contact with nature $\{4.2 .1\}$ This nexus links health and well-being directly and indirectly to all of the SDGs \{e.g. 20.3\} and to issues addressed throughout GEO-6, including in the thematic chapters and with respect to other cross-cutting topics. \{4.2.1\} Box 1.1 explains the methodology used in GEO-6.

\subsection{The Methodology of GEO-6}

GEO-6 uses a modified Drivers-Pressures-State-ImpactResponse (DPSIR) methodology. It combines this methodology with an expanded Response (policy) analysis approach, and an assessment of outlooks combined with bottom-up approaches.

For each of the environmental themes in Part A of GEO-6 ("State of the Global Environment"), the DPSIR approach has been modified from:

(i) a linear conception of the model, to incorporate an understanding of the interactions and feedbacks between the various aspects, as shown by its treatment of cross-cutting issues, and has moved towards a conceptual and systemic framework for integrated assessments (Figure 1.1);

\section{Figure 1.1: The DPSIR approach used in GEO-6}

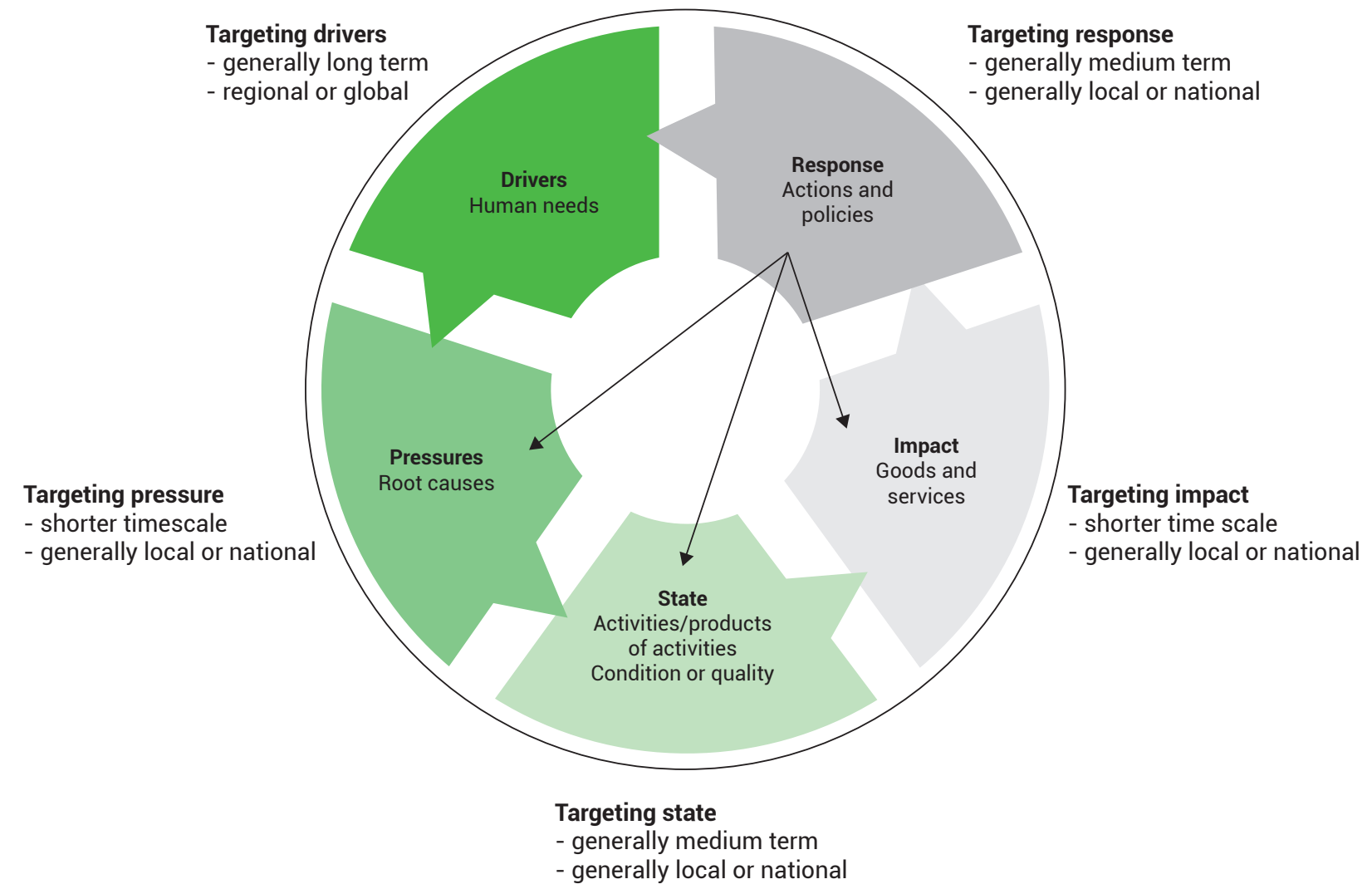

In 1995, UNEP adopted the DPSIR causal framework approach for the GEO assessments. This represents a systems-analysis view in which the driving forces of social and economic development exert pressures on the environment, which change the state of the environment. The changing state of the environment leads to impacts on, for example, human well-being and ecosystem health, which then produces human responses to remedy these impacts, such as social controls, redirecting investments, and/or policies and political interventions to influence human activity. Finally, these responses influence the state of the environment, either directly or indirectly, through the driving forces or the pressures. Existing policies increasingly need to be assessed in terms of how they address the drivers and impacts of environmental challenges.

Source: UNEP (2017b) 
(ii) a purely biophysical analysis of the planet, to an exploration of the links between the health of the planet and human health and well-being. This requires analyzing exposure to certain contaminants. Furthermore, analysis of environmental conditions and health and well-being can reveal underlying relationships between health and the environment. For example, data on underweight children, malnutrition and other food security indicators can inform our understanding of the relationship across climate change, food security and health and well-being; $\{3.6 .2\}$ and

(iii) an environment-only focus, to more explicit incorporation of equity and economic dimensions in the DPSIR framework. The more integrated policy context provided by the SDGs requires a more conscious effort to take the distribution of risks and benefits of action or inaction into account. There are questions of equity (Figure 1.2), such as: What factors result from, mitigate or exacerbate inequalities (drivers)? Who uses and pollutes resources, including sinks (pressure)? How is exposure to benefits and risks distributed (state of

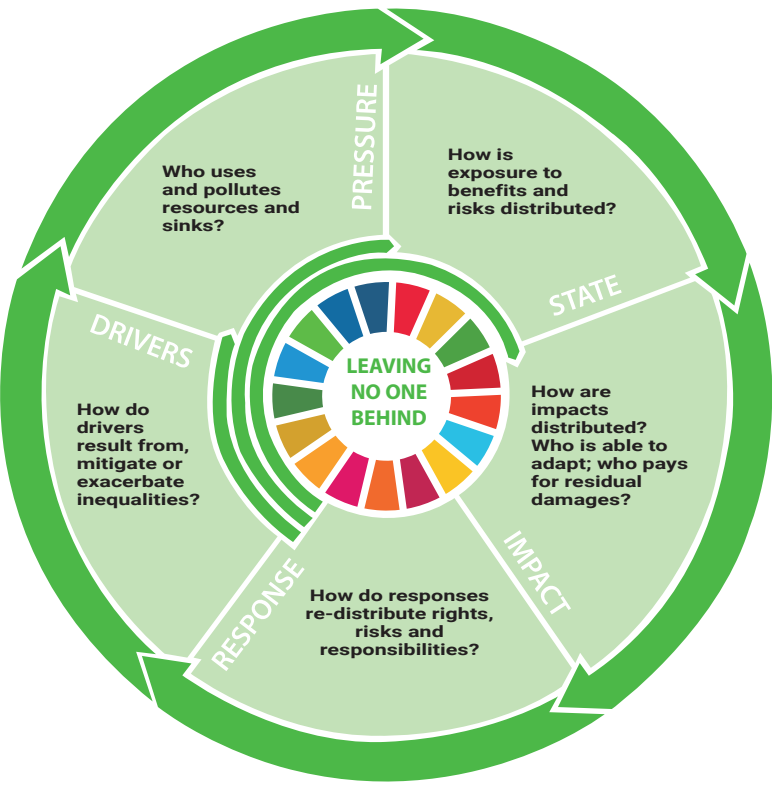

Source : Gupta et al. (2019)

\section{Box 1.1: Approach to assessing policy effectiveness}

Part B of GEO-6 ("Policies, Goals, Objectives and Environmental Governance: An Assessment of their Effectiveness") assesses the potential effectiveness of existing policies and other responses to environmental degradation by applying to a number of case studies a top-down, literature-based evaluation with a bottom-up, indicator-based evaluation. The top-down approach identifies policies, instruments and policy mixes that may serve as examples of good practice which can be applied elsewhere; the bottomup evaluation, based on policy-relevant indicators, complements the analysis and contributes, in particular, to the identification and quantification of action that could perhaps be scaled up (Figure 1.3). $\{10.5\}$

Figure 1.3: Methodological approach for assessing policy effectiveness: top-down and bottom-up

\begin{tabular}{|c|c|c|c|}
\hline \multirow[b]{3}{*}{ Top-down methodology } & \multicolumn{2}{|c|}{ Environmental problem } & \multirow[b]{3}{*}{ tom-up methodolog } \\
\hline & \multicolumn{2}{|c|}{$\begin{array}{c}\text { DPSIR } \\
\text { (including typical responses) } \\
\text { indicators }\end{array}$} & \\
\hline & & & \\
\hline $\begin{array}{l}\text { Which criteria } \\
\text { contributed to } \\
\text { this case's } \\
\text { effectiveness? }\end{array}$ & $\begin{array}{l}\text { What was the } \\
\text { national policy } \\
\text { approach in } \\
\text { which the case } \\
\text { study was } \\
\text { embedded? }\end{array}$ & $\begin{array}{l}\text { What was the } \\
\text { policy type that } \\
\text { was selected for } \\
\text { the specific case } \\
\text { study, and why? }\end{array}$ & \multirow[t]{2}{*}{$\begin{array}{l}\text { Which indicators } \\
\text { are most useful } \\
\text { for monitoring } \\
\text { the effectiveness } \\
\text { of policy } \\
\text { implementation? }\end{array}$} \\
\hline analysıs & \multicolumn{2}{|r|}{ Table 10.1} & \\
\hline $\begin{array}{c}\text { Case } \\
\text { description }\end{array}$ & $\begin{array}{l}\text { National policy } \\
\text { approach }\end{array}$ & Policy typology & $\begin{array}{c}\text { Policy relevant } \\
\text { indicators }\end{array}$ \\
\hline CASES & POLICY DOMAIN & POLICY TYPES & INDICATORS \\
\hline \multicolumn{3}{|c|}{ Evidence base } & \\
\hline
\end{tabular}


the environment)? How are the costs and benefits of environmental use distributed (impacts)? How is the ability to avoid, adapt to and pay for residual damage affected or taken into account (response)? (See Table 3.3 in Chapter 3 of this Technical Summary) There are also economic questions (Figure 1.2), such as: How does the existing economic system contribute to, and mitigate or exacerbate, environmental change (drivers)? How does the existing economic system increase or decrease well-being (pressures)? How is exposure to economic benefit and risk distributed (state)? How large are the economic costs of the impacts, and how are these costs distributed (impacts)? How can rights, risks and responsibilities be redistributed to improve outcomes (response)?

The emerging global architecture for sustainable development and its governance requires a new generation of tools and outlooks that take into account the complexities and interlinkages of humanenvironment systems in order to develop diverse adaptive policies and pragmatic solutions. During the past several decades various methods and approaches have been developed to carry out environmental assessments and produce outlooks in support of policy decisions. The empirical literature on scenarios has evolved, while the policy context has shifted.

Model-based scenario analysis allows systematic exploration of different possible futures or the impacts of proposed policies. However, in most cases the models provide little insight into the role of specific actors or the scope for scaling up current small-scale initiatives. In contrast, methods based on active participation by stakeholders and decision makers reflect their views, interests and expectations. GEO6 benefits from a variety of future-looking methods, using a combination of scenarios and small-scale seeds of change approaches, and demonstrates how the engagement of stakeholders through participatory workshops and crowdsourcing platforms can benefit science-based assessments and outlooks through greater relevance of its findings and recommendations. $\{19.2\}$

In Part C of GEO-6 ("Outlooks and Pathways to a Healthy Planet with Healthy People"), in order to assess future pathways ("outlooks") towards achieving the SDGs and related Multilateral Environmental Agreements (MEAs), the underlying goals are translated into a more concise and quantitative set of targets. Many of the 169 SDG targets have been formulated in clear, quantitative terms, but this is not always the case for some of the environment-related targets. For several issues, such as climate change and biodiversity loss, the MEA targets are more concrete. Accordingly, the quantification of SDG targets can build on related MEAs. When internationally agreed environmental targets are lacking, so-called "science-based" targets can be used that take into account biophysical limits established in

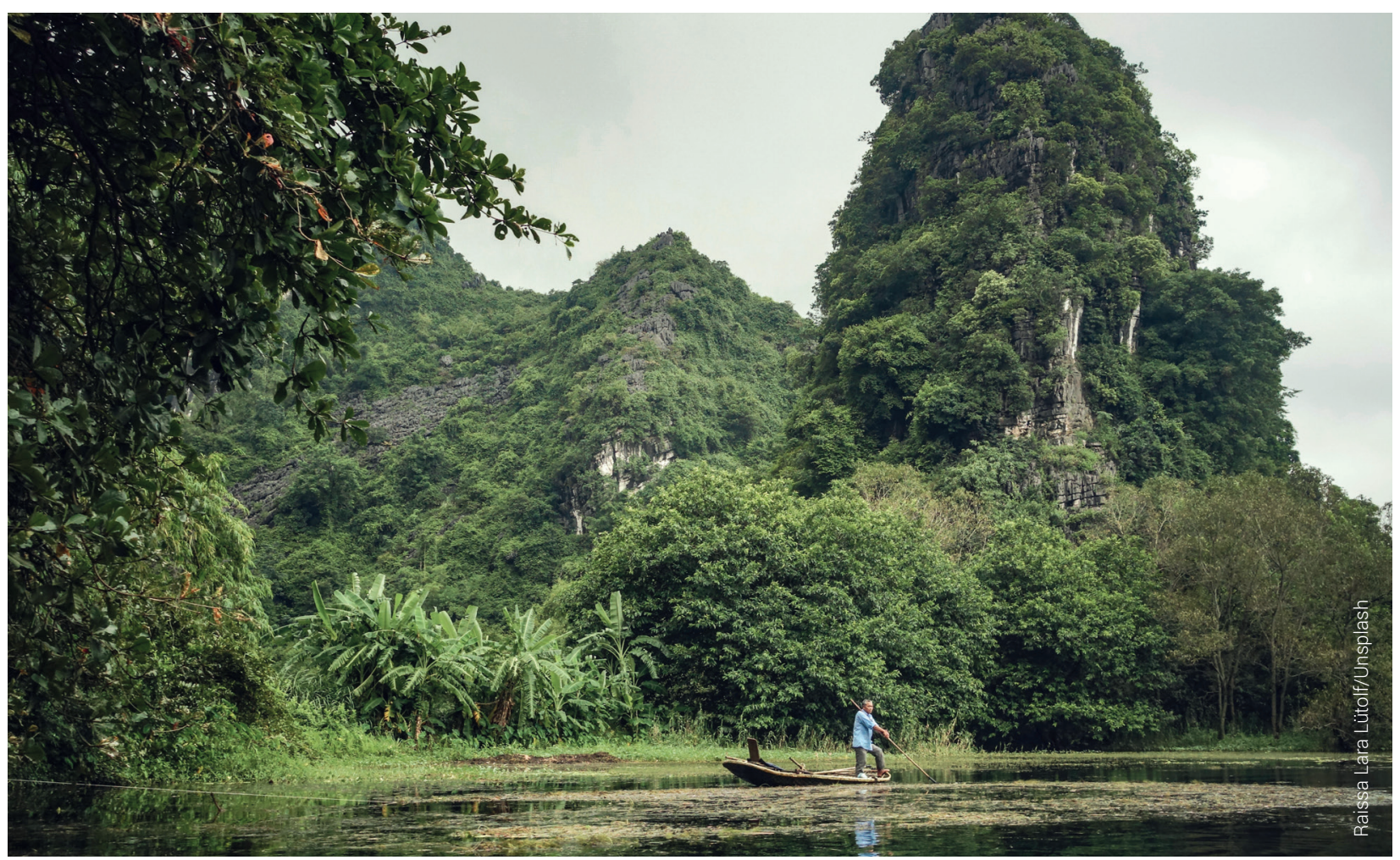


UNEP uses a theory of change to identify, as a result of an intervention, "the causal pathways from outputs through outcomes via intermediate states towards impact" (UNEP 2017a). Strong environmental policies form an integral component of UNEP's theory of change. The theory of change further defines the external factors that influence change along the major pathways to global sustainable development. $\{10.1$, Annex 1-3\} To facilitate the change process, UNEP is producing a number of supplementary publications: GEO for Business, GEO for Cities and GEO for Youth to mobilize change in these key domains.

GEO-6 assesses the literature using a qualitative communication of confidence levels (Figure 1.4): "well established" when there is high agreement in a substantial body of literature of high quality; "established but incomplete" when agreement is high, but there is only a low quantity of literature; "unresolved" when there is a low level of agreement across a significant literature; and "inconclusive" when both the level of agreement and the quantity or quality of the literature are low $\{$ Annex 1-4\}.
Figure 1.4 The four-box model for the qualitative communication of confidence

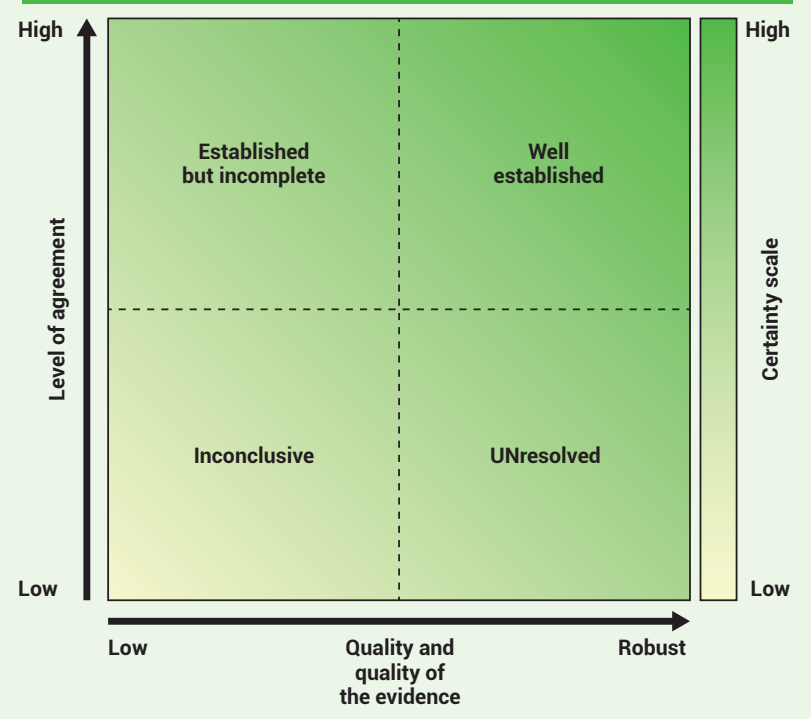

Source: Intergovernmental Science-Policy Platform on Biodiversity and Ecosystem Services [IPBES] (2017) the scientific literature. The collective set of targets can provide a common framework for policy dialogue when it is not possible to fully achieve social objectives and targets without compromising those for the resource base (or vice versa) and allow integrated pathways for progress towards both to emerge. $\{20.4\}$

The GEO-6 scenario assessment focuses on pathways for reaching particular sustainability targets (i.e. targetseeking scenarios) and through this links issues related to food, water and energy systems to the five GEO-6 environmental themes (air, freshwater, land and soil, oceans and coasts, and biodiversity) and the related multidimensional axes of poverty and health. The scenario assessment focuses on human use of natural resources, specifically the challenges addressed by and linked to the SDGs on food systems and agriculture (SDG 2), water (SDG 6) and energy systems (SDG 7). Thus, the use of natural resources is linked to the provision of adequate food, clean water and energy, of the quality and in the quantity required for healthy people (SDG 3), as well as minimizing the environmental impacts that can result from this use (SDGs 13, 14 and 15). Focusing on the use of natural resources can help define a set of environmental targets and pathways that are applicable to the SDGs and related agreements.

Given these complex contextual factors, GEO-6 addresses five policy questions:
* What is the state of the global environment, how is it changing, and what are the major factors and drivers, both positive and negative, influencing these changes?

* How are people and their livelihoods affecting and being affected by environmental change in terms of health, economic prosperity, social equity, food security and overall well-being?

* Are environmental benefits, responsibilities and risks distributed fairly across different regions, socioeconomic groups and genders?

* What are the main responses and policy measures that have been taken to strengthen environmental protection and governance at various levels? How effective have they been in terms of both protecting the environment and taking account of the social and economic dimensions of development?

- What are the critical opportunities and policies, including through the SDGs and MEAs, to transform the global human-environment system so that it becomes more sustainable and to contribute to a healthy planet for healthy people? What are possible pathways to the achievement of the SDGs? What are the likely consequences if no additional actions are taken? 


\section{References}

Gupta, J., Scholtens, J., Perch, L., Dankelman, I., Seager, J., Sánder, F. et al. (2019). Re-imagining the driver-pressure-state-impact-response framework from an equity and inclusive development perspective. Sustainability Science. https://doi.org/10.1007/s11625-019-00708-6.

Intergovernmental Science-Policy Platform on Biodiversity and Ecosystem Services (2017). Progress Report on the guide on the production of assessments (Deliverable 2 (a)). Note by the Secretariat. IPBES/5/INF/6. Plenary of the Intergovernmental Science-Policy Platform on Biodiversity and Ecosystem Services Fifth session. Bonn, 7-10 March. https://www.ipbes.net/system/tdf/downloads/pdf/ipbes-5 inf-6.pdf?file $=1$ \&type $=$ node $\&$ id $=541$

United Nations Environment Programme (2016a). GEO-6 Regiona Assessment for Asia and the Pacific. Nairobi. http://wedocs.unep org/bitstream/handle/20.500.11822/7548/GEO_Asia_Pacific_201611. pdf? sequence $=1$ \&isAllowed $=y$

United Nations Environment Programme (2016b). GEO-6 Regional Assessment for Africa. Nairobi. http://wedocs.unep. org/bitstream/handle/20.500.11822/7595/GEO_Africa_201611. pdf? sequence $=1$ \&isAllowed $=y$

United Nations Environment Programme (2016c). GEO-6 Regional Assessment for North America. Nairobi. http://wedocs.unep.org/ bitstream/handle/20.500.11822/7611/GEO_North_America_201611. pdf?sequence $=1$ \&isAllowed $=y$

United Nations Environment Programme (2016d). GEO-6 Regional Assessment for Latin America and the Caribbean. Nairobi.

http://wedocs.unep.org/bitstream/handle/20.500.11822/7659/GEO LAC_201611.pdf?sequence=1\&isAllowed=y.
United Nations Environment Programme (2016e). GEO-6 Regional Assessment for West Asia. Nairobi. http://wedocs.unep.org/ bitstream/handle/20.500.11822/7668/GEO_West_Asia_201611. pdf? sequence $=1$ \&isAllowed $=y$.

United Nations Environment Programme (2016f). GEO-6 Regional Assessment for the Pan-European Region. Nairobi. http://wedocs. unep.org/bitstream/handle/20.500.11822/7735/unep_geo_regional_ assessments_europe_16-07513_hires.pdf?sequence=1\&isAllowed=y.

United Nations Environment Programme (2017a). Use of Theory of Change in Project Evaluations: Introduction. Nairobi. http://wedocs. unep.org/bitstream/handle/20.500.11822/7116/11_Use_of_Theory_of Change_in_Project_Evaluation_26.10.17.pdf? sequence=6\&isAllowed=y.

United Nations Environment Programme (2017b). Guidelines for Conducting Integrated Assessments. Nairobi. https://wedocs.unep. org/bitstream/handle/20.500.11822/16775/IEA_Guidelines_Living_ Document_v2.pdf

United Nations Environment Programme (2019a). Global Environment Outlook - GEO-6: Healthy Planet, Healthy People. Nairobi. https://wedocs.unep.org/bitstream/handle/20.500.11822/27539/ GEO6_2019.pdf?sequence=1\&isAllowed=y

United Nations Environment Programme (2019b). Global Environment Outlook - GEO-6: Summary for Policymakers. Nairobi. https://wedocs.unep.org/bitstream/handle/20.500.11822/27652/ GEO6SPM_EN.pdf?sequence=1\&isAllowed=y. 
